\title{
New Technological Scheme for Dredging Process
}

\author{
Igor Z. Maslov, Valentin I. Chimshir, Iryna M. Smyrnova, Andrii I. Naydyonov
}

\begin{abstract}
The present investigation aims to propose adevelopment of new technology for marine dredging operations. The main problem of dredging process connected with profit increase and reduction of time required to produce the necessary amount of soil. It is shown in the article that these can be achieved by changing the technology of slurryprocessing and transporting only. The specific concentration of water in the slurry reductionleads to an increase of the most important working indicator - the productivity of the dredger. Under the same conditions the dredging vessel's operating time can be reduced by increasing the concentration of soil in the slurry. For this purpose, a new technological scheme was developed. It was describedhow to use the schemefor two typical operational modes of the vessel.The first one describes the process of slurry extraction and transportation through a nearshore deflate pipeline, and the second one, when the extracted soil enters the cargo hold of the dredger.
\end{abstract} separation unit, new dredging technological scheme.

\section{INTRODUCTION}

The underwater soil extraction process by dredgers is used in all regions of the planet. This process determines the topography in the zones of rivers, lakes, estuarine and coastal marine areas. Dredging can change the main ecological characteristics of water basins and is a substitute for various natural geomorphological processes (change of depth and fairways [1], removal of sediments [2], descending of salinity [3] etc.). Every year only for USA shelf 500 million tons are produced by dredgers[4] and 67 million tons of various non-metallic building materials in Japan [5]. The production quality of the dredger, regardless of its design, is directly determined by the technological scheme that is used during dredging process [6]. The operations of soil extraction, its processing and transportation give an ability to adjust the two most important indicators of the dredger effectiveness - the duration and the cost of the exploitation. Currently, when carrying out dredging operations, two categories of vessels that are fundamentally different from each other can be used. These categories can be considered as classes of dredgers.

Revised Manuscript Received on December 30, 2019.

* Correspondence Author

Igor Z. Maslov, Associate Professor and Head of Ship`s Power Plants Operation and Systems Department of the Danube Institute of the National University “Odesa Maritime Academy”, Izmail City, Ukraine.

Valentin I. Chimshir, Associate Professor and Director of the Danube Institute of the National University "Odesa Maritime Academy", Izmail City, Ukraine.

Iryna M. Smyrnova, an Associate Professor and Deputy Director for Scientific Work of the Danube Institute of the National University "Odesa Maritime Academy", Izmail City, Ukraine.

Andrii I. Naydyonov, Senior Lecturer at Department of Ship Power Plants and Systems of the Danube Institute of the National University "Odesa Maritime Academy

(C) The Authors. Published by Blue Eyes Intelligence Engineering and Sciences Publication (BEIESP). This is an open access article under the CC BY-NC-ND license (http://creativecommons.org/licenses/by-nc-nd/4.0/)
Keywords: concentration of water in a slurry, dredger,

The first class is corresponding to dredgers that carry out soil excavation without transporting it to big distances. The maximum depth of excavation for these vessels reaches 30 mon rivers or water channels, and $60 \mathrm{~m}$ in the sea. The second class includes those vessels, which are used for the soil excavation and delivery to the alluvium map - the place of its subsequent storage, i.e. ashore or underwater landfill. The difference between these two classes of dredgers enclosed inthe technological scheme which isused for dredging process. They alsodiffer in the final technical solutions which areapplied to the operation of main devices, components and mechanisms.

The main problem in the operation of all dredgers consists in the fact, that huge and useless volumes of water are always extracted and transported with soil. Typically, the specific concentration of water in the slurry is $60-75 \%$. For this reason, the efficiency of dredging companies can increase with the use of new technological schemes for separating water from the slurry. A new technology dedicated for increase the consistency of soil in the slurry under the conditions of the vessel's operation can reduce the energy costs of soil extraction, increase the productivity of the dredger and cut the cost of its work by reducing the time of the whole working cycle.

\section{II.PROBLEMSTATEMENT}

The problem of dredger's operational quality improvement in scientific publications is described very rarely. Usually, books, articles and monographs consider particular problems and their solutions only. Such problems include: hydrological processes of sedimentation or the motion of a multiphase flow of solid particles with water [2], [7], [8],mechanical methods of the underwater soil destruction [5], calculation of main parametersfor dredging pump or its operating modes [9], [10]and hydraulic calculation of pipelines, that are usedfor slurry transportation [9], [11]. An analysis of technological schemes of the dredgers operational modes shows that all methods of industrial destruction of the compacted layer of soil surface are mechanical. Publications often consider the slurry sedimentation during its movement in pipelines, but at the same time, no specific recommendations are given on the minimum concentration of water at which the slurry can be transported without precipitation of unmovable soil layer. The very parameter determines directly the cost of dredging and gives an ability to find out the required amount of energy and the complexity of the technological transportation scheme, which will be used to receive necessary amount of soil. In accordance with the experimental data, obtained by Turner[9] an analysis of dredgers productivity depending on the length of the pipeline used for slurry transportation was done. 


\section{New Technological Scheme for Dredging Process}

As a result, it was found that, regardless of the technological scheme of soil extraction used on the dredger, the total output decreases quickly when the lengthof the hydraulic pipeline for slurrytransportation increases. For this reason, the main problem of increasing the efficiency of the dredger is to reduce the volume of water in the slurry. The solution of this problem can be a universal technological scheme development for slurry separation in the area of soil extraction. The installation of additional separating unit can be considered as complementary resource to improve existing dredging technologies.

\section{METHODOLOGY}

The flow of slurry can be divided into homogeneous and heterogeneous with mobile or fixed sedimentary layer. The steady state for each of these flows is directly determined by the fluid mechanics regime of movement inside the pipeline. The uniform distribution of large fractions in the flow, as well as precipitation, is characterized by the highest energy consumption for the slurry movement.

The basis for the developed new technological scheme of dredging is a combination of two processes. The first process is hydromechanical and is based on the principle of tangential swirling of the slurry flow due to the kinetic energy that it received from the vessel's dredging pump. The soil particles during rotation inside the cyclonewill move tothe walls direction and water can be discharged from its central volume.

The second process is mechanical and it is based on the soil extraction from water when the slurry enters the compound high-pressure zone. The process of slurry compression goes in a conical working chamber due to the rotation of the Archimedes' screw. The separator is shown in Figure 1.

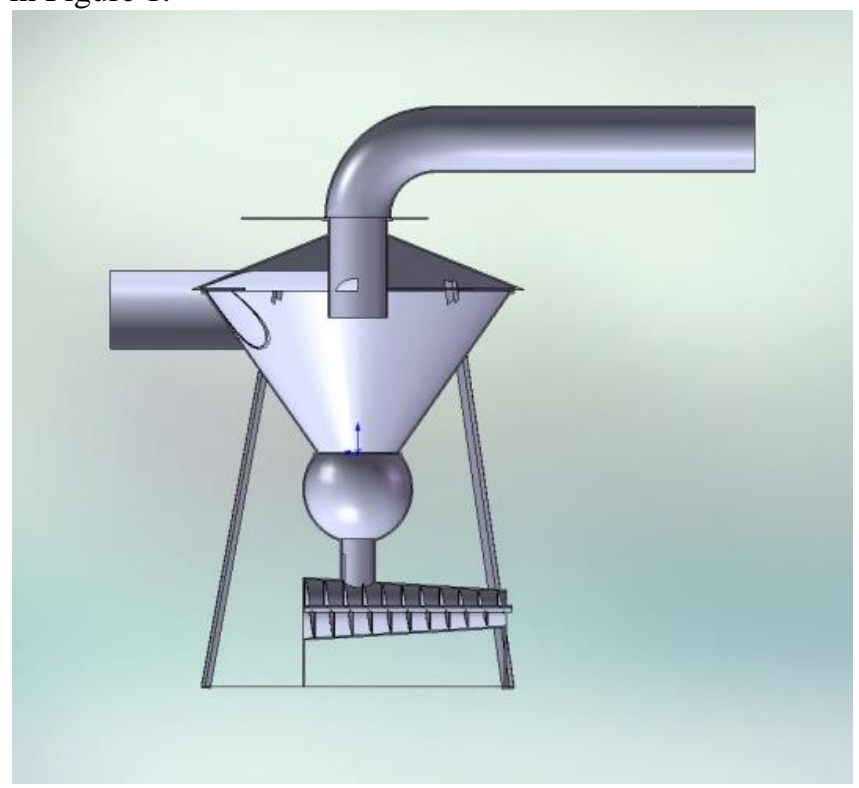

Fig. 1. Slurry separator

Flow high speeds maintaining that provide high performance of slurry transportation systems is very expensive from economical point of view. This excessive energy can be used to spin the flow in a centrifuge. During rotation, excessive water can be discharged overboard. An increase of the soil concentration in the slurry will lead to an increase in the volumetric flow-rate of the final soil discharge. Schematic diagram for the slurry separation is shown in figure 2 .

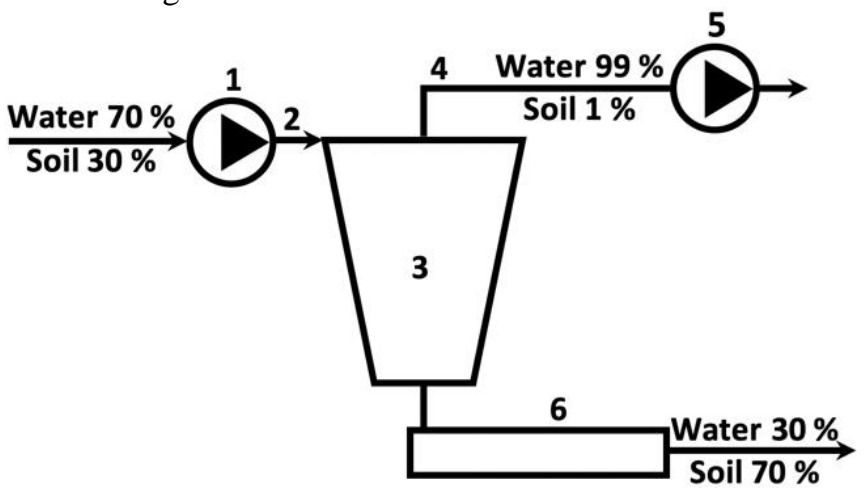

Fig. 2. Schematic diagram

The main amount of energy required for the operation of the separation unit is transferred to the slurry when it is lifted aboard the vessel by the dredging pump 1 . In this flow, the maximum soil concentration cannot exceed $30 \%$. Throughthe suction pipe 2, the slurry enters the cyclone chamber3 of the plant. In this chamber, due to the rotation of the flow, the primary separation of water and soil occurs. In the upper central partof the cyclone 3 through the pipeline 4 due to the operation of the buster pump 5, water is taken off. This water can be discharged overboardimmediately. In this flow, the average soil concentration should not excess $1 \%$.

From the bottom part of cyclone, the soil with residual water moves due to gravity to the mechanical extraction unit 6. Its main elements are the Archimedes screw rotating at low speeds and the rigid walls of the chamber. Since the drive of all dredgers has a big power reserve, the rotation speed of the release screw can be set in any technologically necessary range. By adjusting the area of the output section in the working chamber 6 and the rotation number of the squeezing screw, any final concentration of water in the slurry can be stated. From the hydromechanics point of view the water concentration equals $30 \%$ is enough to transport the slurry.

From the energy point of view, the optimal structure of the multiphase slurry flow is the uneven distribution of soil particles in the water. With this distribution, the deposition of solid particles of the soil compared to the case of a stationary fluid will be much slower.

The sedimentation of solid layer during motion of themultiphaseflow of slurry can be described best of all by the sinking velocity of particle in a liquid at rest at a temperatureof $10{ }^{\circ} \mathrm{C}$. It can be named as hydraulic particle size of the soil $V_{S}$. The values of this parameter for sand, silt and clay are shown in the table I.

Table I Hydraulic particle size $V_{s}$

\begin{tabular}{|c|c|c|}
\hline Soil & $D, \mathrm{~mm}$ & $V_{S}, \mathrm{~m} / \mathrm{s}$ \\
\hline \multirow{3}{*}{ Send } & 1 & 0,1 \\
\cline { 2 - 3 } & 0,5 & 0,053 \\
\cline { 2 - 3 } & 0,1 & 0,0069 \\
\hline \multirow{3}{*}{ Silt } & 0,05 & 0,0017 \\
\cline { 2 - 3 } & 0,01 & $7 \cdot 10^{-5}$ \\
\hline
\end{tabular}




\begin{tabular}{|c|c|c|}
\hline \multirow{3}{*}{ Clay } & 0,0027 & $5 \cdot 10^{-6}$ \\
\cline { 2 - 3 } & 0,001 & $7 \cdot 10^{-7}$ \\
\hline
\end{tabular}

Velocity of soil sedimentation can be calculated as

$$
V_{S E D}=\beta V_{S}=\left(-C_{F} C_{S}+\sqrt{C_{F}^{2} C_{S}^{2}+\left(1-C_{S}\right)^{3}}\right) V_{S}
$$

$\beta$-factor, depicting the structure of a moving flow, $V_{S}$ hydraulic particle size of the soil, $\mathrm{m} / \mathrm{s}, C_{S}$ - soil volumetric concentration in the flow, \%; $C_{F^{-}}$dimensionless hydrodynamic flow characteristic.

The hydrodynamic characteristic of the flow $C_{F}$ for small particles of soil $(\mathrm{D}<0.12 \mathrm{~mm})$ equals $C_{F}=4.5$, and for large particles of soil $(\mathrm{D}>10 \mathrm{~mm})$ equals $C_{F}=0.23$. For particles of medium size $(0.12 \mathrm{~mm}<\mathrm{D}<10 \mathrm{~mm})$ it can be calculated as

$$
C_{F}=\frac{24\left(4.5+0.0125 \frac{V_{S} D}{v} \sqrt{C_{D}}\right)}{\frac{V_{S} D}{v} C_{D}}
$$

$C_{D^{-}}$drag factor of the soil particle; $v$ - kinematic viscosity of the liquid $\left(\mathrm{m}^{2} / \mathrm{s}\right) ; D$ - diameter of particle $(\mathrm{m})$.

The values of drag factor $C_{D}$ calculated for single particle of sand and gravel depending on Reynolds parameter are shown in figure 3.

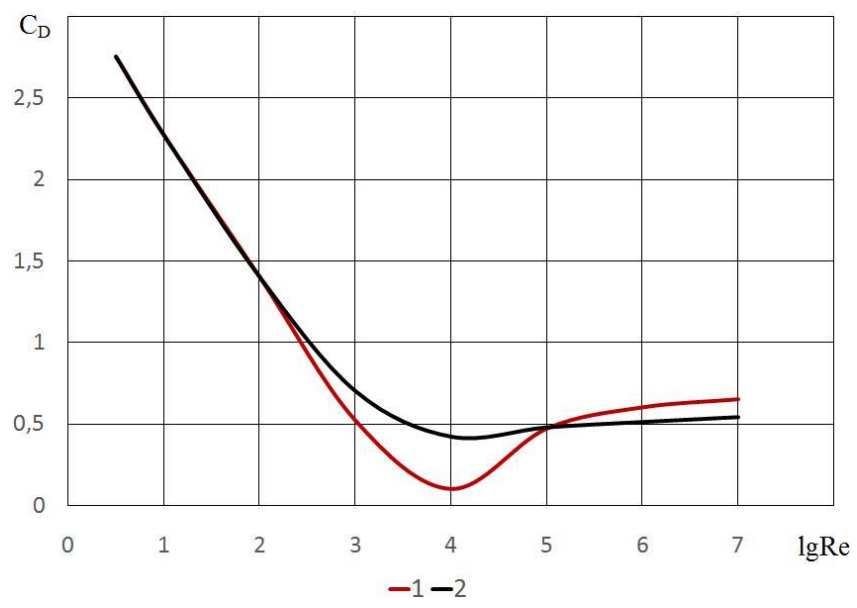

Fig. 3 Drag factor $C_{D}$ for sand (1) and gravel (2)

\section{RESULTS}

The main characteristic of the multiphase flow of soil and water swirling process is the time when soil particles will be displaced to the walls of the cyclone. The calculation results of this time for different values of the velocity of the slurry supply into the working chamber are shown in Figure 4.

An increase in the slurry supply velocity to the cyclone significantly reduces the process of its separation. In this case, soil particles in a nonlinear dependence on the supply velocity begin to shift faster from the cyclone axis of symmetry to the rigid walls. As it can be seen in the diagram, the operating values of the inlet velocity should exceed the value equals $5 \mathrm{~m} / \mathrm{s}$. When an inlet velocity equals $3 \mathrm{~m} / \mathrm{s}$ the separation time is almost in 2.5 times longer than the same value at the velocity equals $5 \mathrm{~m} / \mathrm{s}$. When inlet velocity equals $6 \mathrm{~m} / \mathrm{s}$ the difference is observed in 4 times longer. The optimal value of the slurry supply velocity into the separator is $7 \mathrm{~m} / \mathrm{s}$. In this case, themaximum time for soil separation from water in the largestcross-section of the working chamber of the cyclone equalscross-section of the working chamber of the cyclone equals2 seconds only.

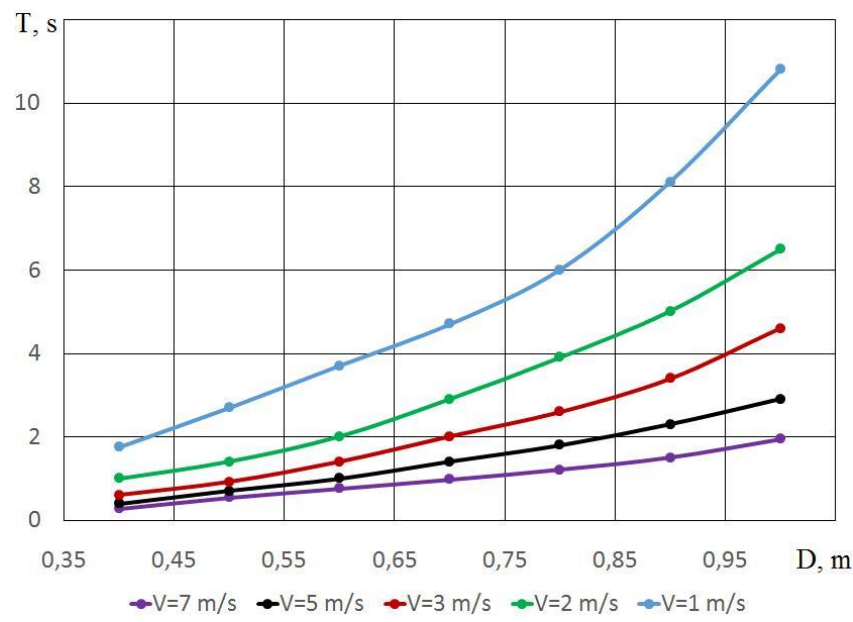

Fig. 4 Duration of slurry treatment

The main part of the kinetic energy whichslurry flow receives inside the vessel's dredging pump is spent for hydraulic losses inside the cyclone and separation of the soil from the water. These hydraulic losses were measured experimentally. Figure 5 shows how they vary depending on different values of the flow-rate of the slurry in the discharge pipeline. The resulting relationship between energy loss and consumption obeys a parabolic law.

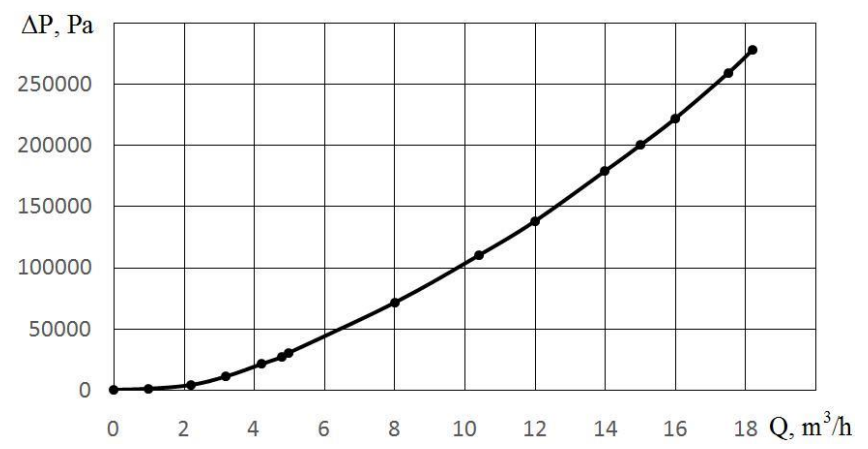

Fig. 5 Pressureloss

During experiments the value of the cyclone factor of hydraulic resistance $\zeta$ was found using the equation

$$
\zeta=\Delta \mathrm{P} /\left(0.5 \rho V^{2}\right)
$$

$\Delta \mathrm{P}$ - pressure difference at the inlet and outlet of the cyclone, $\mathrm{Pa} ; \rho$ - density of the slurry, $\mathrm{kg} / \mathrm{m}^{3} ; \mathrm{V}$-average speed at the inlet of cyclone, $\mathrm{m} / \mathrm{s}$.

As it can be seen in Figure 6 with an increase in the Reynolds parameterfactor of hydraulic resistance $\zeta$ remains almost unchanged. This dependence is shown in Figure 6 and the average factor of hydraulic resistance of the cyclone equals $\zeta=19.5$. The quality of working process of the vessel's plant for water and soil separation is directly determined by the hydrodynamic pressure of the slurry flow at its inlet area. The experimental dependence between the value of pressure in the inlet cross-section of the plant and the final soil 


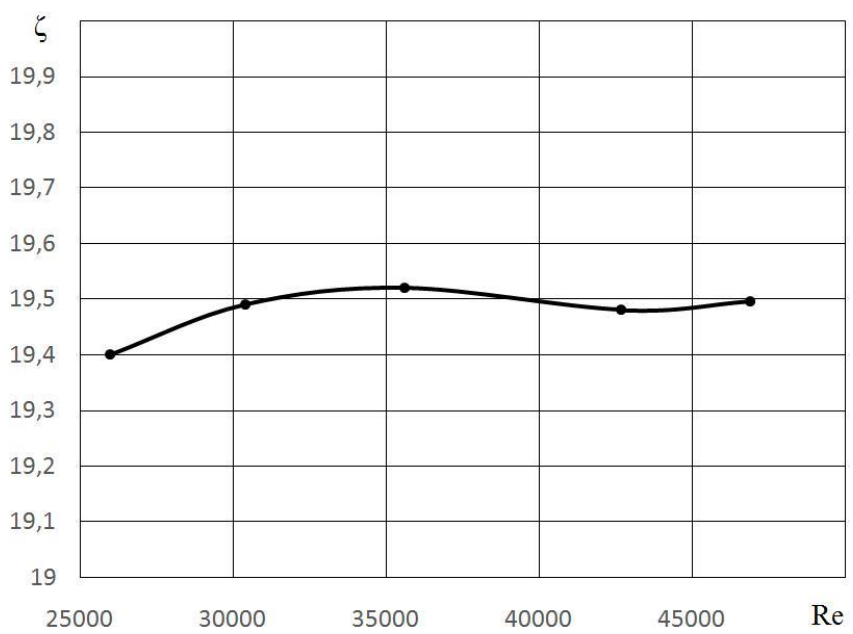

Fig. 6 Hydraulicresistanceof the cyclone

concentration in the slurry is shown in Figure 7. The graph shows how the ratio (curve 1) of the flowrate of the separated water $Q_{W}$ to the total flow rate of the slurry $Q_{S}$ changes when pressure arises at the inlet to plant. At thefig.7there is dependence 2. It describes the quality of the slurry treatment process. At the beginning, when the pressure of the slurry grows the relative value of soil concentration $\operatorname{cin}$ the water discharged is descending. It takes its minimum value at water head equals $\mathrm{H}=25 \mathrm{~m}$, and then begins to grow. The increase of soil concentration in the slurry was caused by additional turbulence of the flow and formation of a large-scale vortexes motion.

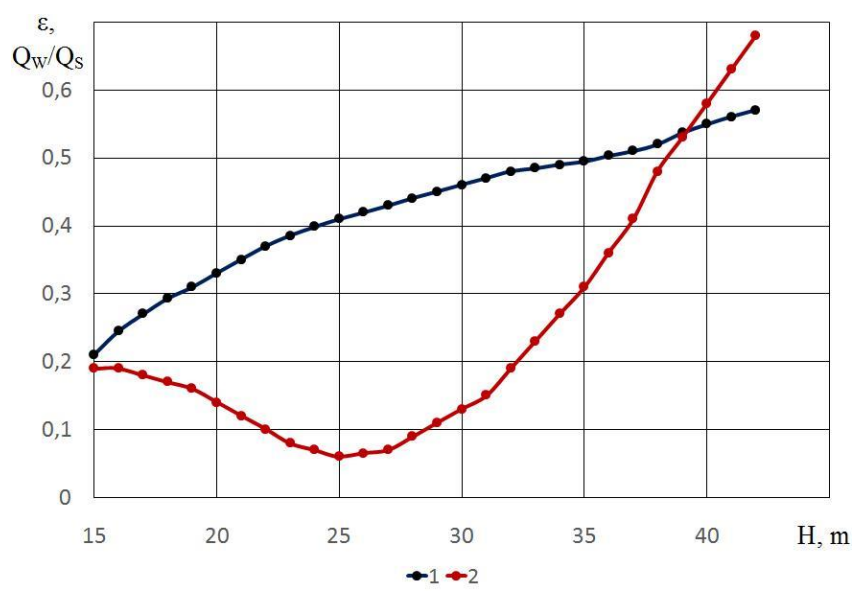

Fig. 7 Plant output and quality of slurry separation

\section{DISCUSSION}

The production efficiency of any type of dredger can be improved by changing the technology for treatment and slurry transportation only. Reducing the specific concentration of water in the slurry, ceteris paribus, leads to an increase in the most important working indicator - the output of the dredger.

Additional separation of the multiphase slurry flow should be carried out still on the stage of its transportation through the dredger's discharge pipeline.

When operating dredgers, special attention must be paidto theinstallation area for the developed unit of slurry separation. Depending on the requirements for the residual concentration of water in the slurry, two technological schemes for the dredger operation can be used. They are shown in figures 8-9.

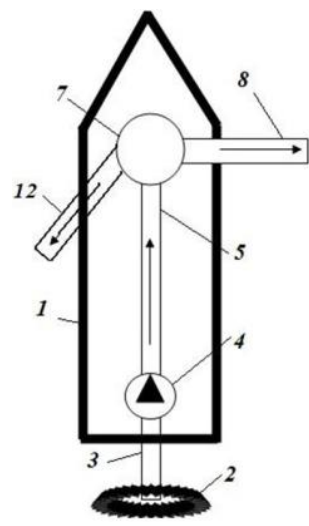

Fig. 8 Technological scheme for the dredger

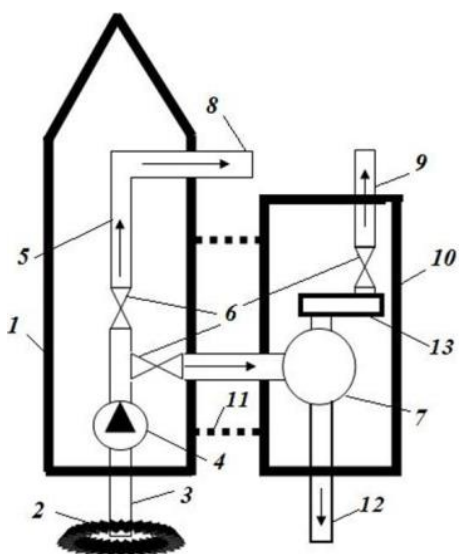

Fig. 9 Technological scheme for the pontoon

On these diagrams: 1 - dredger; 2 - milling cutter; 3 suction section of the slurry pipe; 4 - dredging pump; 5 pressure section of the slurry pipe; 6 - hydraulic fittings; 7 plant for slurry separation; 8 - slurry transport pipeline; 9 couloir or mechanical conveyor; 10 - pontoon; 11 - mooring mechanisms; 12 - water discharge pipeline; 13 - unit for mechanical extraction.

At the first scheme the installation areafor the separation unit (Fig. 8) is the deck of the dredger. In this case the residual concentration of the water has to exceed 30 $\%$ and the slurry should be subsequently transported in a standard operational mode. The installation of a separation unit on the deck of the dredgerunambiguously increases the performance of the transportation system in the slurry transportation pipeline. With this connection technology, the slurry separation plant should not contain a unit for mechanical slurry treatment.

When carrying out ship repairing works using the first technological installation scheme for the dredger(Fig. 8), the separation unit must be connected to the dredger deck with a rigid connection (welding or bolt connection). All pipesjunction must be provided with the use offlange connections. The second installation scheme (Fig. 9) is the deck of a separate pontoon. It must be moored to the dredger with a fixed connection. During the operation of this technological scheme, the residual concentration of water will be minimal (at least 20\%).

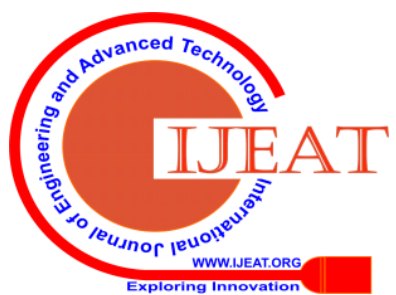


The finalslurry cannot be transported in the usual way due to the operation of the ship's dredging or buster pumps. For this reason, one of the options for slurry transportation from the vessel's separator to the cargo hold may be a long couloir, which uses the principle of viscoplastic flow movement due to gravity.

The total friction force between the slurry flow and thewalls of longcouloircan be calculated as

$$
F=P l \tau
$$

$\mathrm{P}$ - perimeter of walls, contacting with slurry, $\mathrm{m}$; $l$ - total perimeter, $\mathrm{m}$; $\tau$ - the shear stress, $\mathrm{Pa}$.

An analysis of this expression allows one to make a conclusion that round and semicircular shapes are preferable for the walls of a long couloir. For a stated value of area, they have a smaller wetted perimeter and possess less resistance to the transported soil.

The maximum distance for slurry transportation during dredging is directly determined by the angle of inclination of the couloir. The smaller this angle is the greater the transportation distance will be. The optimal value for this angle should correspond to a range from 25 up to 33 degrees. The maximum distance at which it is possible to transport the slurry is $65 \mathrm{~m}$. Construction of couloir, which is used during dredging is limited by the level of excitement of the water surface.

A new common and universal technological scheme which was developed for dredging process is shown in Figure 10.On this diagram: 1 - dredger; 2 - mechanical mill; 3 -inlet part of the dredger's slurry pipeline; 4, 18, 28 - flow and vacuum gauges; 5, 14, 19, 25, 30 - automatically controlled valve; 6 -main dredging pump; 7, 13, 29 pressure gauge; 8 -automatic control tee regulator; 9, 21 slurry transporting pipeline;10 - auxiliary pipeline;11, 27 buster slurry pump; 12 - vacuum gauge; 15 - pipeline forthe supply of slurryto the separator; 16 - working chamber of a cyclone; 17 - pump for the drainage of separated water; 20 unit for slurry mechanical extraction; 22 - flowmeter; 23 pipeline for soil removal; 24, 26 - drainage line for separated water. Its main advantage consists in the possibility of use, both in the usual mode of soil transportation over long distances with a big water consistence in a slurry, and in the mode of direct storage of soil in the hold of the vessel when the slurry is squeezed to a minimum water concentration. As an example, in Figure 10, a variant of the mechanical milling of the soil during its extraction is considered. This variant is most common in dredging but not principal for the operation of the separation unit and the technological scheme in the whole. The developed technology will be working at the same way with any process of underwater soil extraction. The technological scheme provides the installation of a separation unit not on the vessel's board, but on a separatepontoon. This approach has three advantages. The first oneconsists in the autonomous work of the separator. Thesecond onegives a mobility of use when dredging is carried out over long distances and simultaneously by several vessels. The third one consists in the possibility of soil transporting to a shore during the operation of the dredger at a shallow depth.

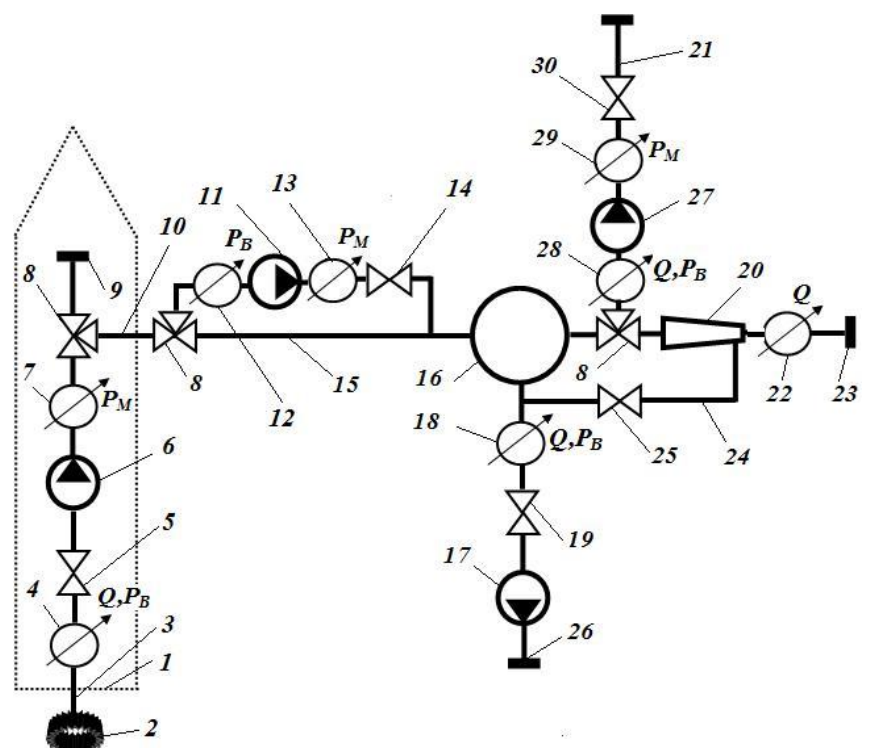

Fig. 10 Technological scheme for dredging process

The developed technological scheme operates as follows:on dredger 1 , due to the operation of the rotating mechanical cutter 2 and main dredging pump6, the multiphase flow of soil with water inflowsto the suction line of the vessel's dredging pipe 3. The vacuum pressure and flow-rate of the slurry in suction line 3 are measured with the use of corresponding measuring devices - a flowmeter and a vacuum gauge 4 . The value of slurry flow-rate is regulated by an automatically controlled valve 5 . The pressure of the vessel's main dredging pump is controlled by a pressure gauge 7 . In the case when dredger is operating in its own normal process mode, i.e. without the use ofslurry separation unit,all slurry flow by tee reducer 8 will be directed towards thepipeline 9 . In this case, the treatment of the soil-carrying flow is not performed.

In the case when slurry separation unit is connected with the dredger's slurry pipeline, the main flow of mined soil with watershould be directed by automatic turning the tee regulator 8 towards the auxiliary pipeline 10 . If the measurements of pressure gauge 7 correspond to the inlet range of dynamic working parameters for the slurry separator, the flow through pipeline 15 is directed to its further processing. Very often, due to large hydraulic losses or small values of pressure developed by a main dredging pump, the flow of the slurry would not have the necessary kinetic energy. For this reason, with the use of an automatic tee regulator 8 , it should be directed to the auxiliary soil boost pump 11. The values of its suction and discharge pressures are controlled with the use of vacuum gauge 12and manometer 13. The pressure-flow hydraulic characteristic can be regulated by an automatically controlled valve 14. Passing by the auxiliary boost pump 11, the flow of the slurry with the necessary operating parameters enters the working chamber of the cyclone 16 . During the initial separation of the slurry, the separated water is discharged from the working chamber of the cyclone with the use of the pump 17. In order to prevent the operating mode from breaking inside the cyclone, the developed vacuum pressure and the flow-rate of the separated water should be controlled by a vacuum gauge and flow meter 18. 


\section{New Technological Scheme for Dredging Process}

Regulation of these parameterscould be provided by opening or closing an automatically controlled valve 19 .

From the cyclone, depending on the required value of the final concentration of water in the slurry, the flow through the tee regulator 8 is directed either to the mechanical extraction unit 20 or to the transporting pipeline 21.If the requirements for the level of soil separation from water are high, then the secondary stage of slurry separation is implemented in the mechanical extraction unit 20.

At the discharge section of unit 20, separated soil enters the conveyor line or couloir 23, and its mass flow-rate is controlled using a flowmeter 22. During mechanical extraction, the separated water along line 24 after automatic opening of valve 25 is sucked in by pump 17, and after mixing with the general flow from the cyclone chamber is discharged overboard throuhpipeline 26.

In the case when the extracted soil should to be transported through the pipeline to theshore, and not stored in a hold, the flow of the slurry from the cyclone with an already lowered water concentration through the automatic tee regulator is sent to the transporting pipeline 21 . The initial pressure of slurry during the passage of the cyclone working chamber is completely consumed, and, for this reason, a pump 27 is used on line 21. Its suction pressure and the developed flow rate are controlled by the vacuum gauge and a flow meter 28.

Depending on the distance to the shore final point of slurry delivery the hydraulic pressure-flow characteristic of the pump is controlled using a pressure gauge 29. Regulation is carried out using an automatically controlled valve 30 .

\section{CONCLUSIONANDFEATURESCOPE}

The efficiency of the dredger output depends on the concentration of soil in the slurry. These parameters can be increased when the slurry processing technological scheme described in the article will be used at the area of underwater soil extraction.

Profit increase and operating time reductionfor any type of dredger can be achieved by changing the technology for soil dredging and slurry transportation only.Reduction ofwater specific concentrationin the slurry, ceteris paribus, leads to an increase in the most important working indicator - the output of the dredger.

The feature investigations should be directed to the solution ofthe problem ofsoilunloading from the cargo hold ofdredgers. Very often, during soil transportation inside the cargo hold, takes place a problem of strong compaction of the upper layers of the soil. This happens mainly due to the properties of the soil and due to the climatic conditions of its transportation. For pre-treatment of soil before the discharge process, inefficient mechanisms that work on the principle of mechanical destruction due to vibrationare used.

\section{REFERENCES}

1. L. E. Cronin, Estuarine Research, 1st ed. vol. II,Academic Press, 1975.

2. J. C. Winterwerp, C. Kranenburg, Fine Sediment Dynamics in the Marine Environment, 1st ed. vol. 5, Elsevier Science, 2002.

3. H.H.G. Savenije, Salinity and Tides in Alluvial Estuaries. Elsevier Science, 2005.

4. T. Kusuda, H. Yamanishi, J. Spearman, J. Gailani, Sediment and Ecohydraulics, 1st ed. vol. 9, INTERCOH 2005, Elsevier Science, 2007.

5. I. Twardowska, H.E. Alen, A.F. Fettrup, W.J. Lacy, Solid Waste: Assessment, Monitoring and Remediation, 1st ed. vol. 4, Pergamon, 2004.

6. R.N. Bray, A.D. Bates, L.M. Land, Dredging. A Handbook for Engineers. 2nd ed., Dutterworth-Heinemann, 1996.

7. M. Wiley. Estuarine Processes. Circulation, Sediments, and Transfer of Material in the Estuary. 1st ed. vol. II, Academic Press, 1976.

8. J. Maa, L. Sanford, D. Schoellhame, Estuarine and Coastal Fine Sediment Dynamics, 1st ed. vol. 8, INTERCOH 2003, Elsevier Science, 2006.

9. T. M. Tomas. Fundamentals of hydraulic dredging. ASCE Press. Reston. Virginia, 1996.

10. K. C. Wilson, G. R. Addie, A. Sellgren, R. Clift.Slurry Transport Using Centrifugal Pumps. 3rd ed. Springer, 2008.

11. P. Bruun, Developments in Geotechnical Engineering. Stability of Tidal Inlets: Theory and Engineering. 1st ed. vol. 23,Elsevier Science, 1978.

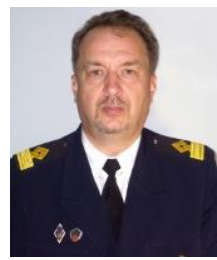

\section{AUTHORS PROFILE}

Igor Z. Maslov is currently working as an Associate Professor andHead of Ship`s Power Plants Operation and Systems Department of the Danube Institute of the National University "Odesa Maritime Academy”, Izmail City, Ukraine. He earned his PhD degree from National University "Odesa Maritime Academy”(2016).Hisresearch interests includedredging technologies for different conditions of vessel operation, design and modernization of main dredger's technical systems, fluid mechanics of multiphase flows, complex analysis of dredging process for different vessels, IT technologies in dredging.ORCID: 0000-0003-17596077. E-mail: sartfm@yahoo.com. Mobile:+380673693946

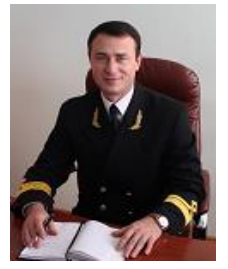

Valentin I. Chimshir is currently working as an Associate Professor and Director of the Danube Institute of the National University "Odesa Maritime Academy", Izmail City, Ukraine. He earned his PhD degree fromOdessa National Maritime University (2009) andDoctor of Science degree from Odessa National Maritime University (2017). His research interests includeproject management on sea transport,development of new management methods for transport, new management methods development for shipbuilding. ORCID: 0000-00033621-2702, E-mail: chimshir@ukr.net. Mobile:+380965549377

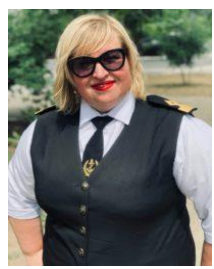

Iryna M. Smyrnova is currently working as an Associate Professor and Deputy Director for Scientific Work of the Danube Institute of the National University "Odesa Maritime Academy", Izmail City, Ukraine. She earned her $\mathrm{PhD}$ degree from Central Ukrainian State Pedagogical University (2005) andDoctor of Science degree fromUkrainian National Academy of Education Sciences(2018). Her research interests include water transport management, the impact of the vessel's technical systems operation onto the environmental indicators, methods for assessing the effectiveness of ships, monitoring systems for technical operations in sea transport. ORCID: 0000-0003-20855391E-mail: phd.smyrnova@gmail.com. Mobile: +380671628575

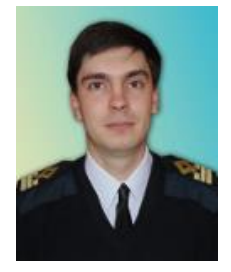

transporting.ORCID: NaydyonovAndrii@gmail.com. Mobile: +380632367342
Andrii I. Naydyonovis currently working as aSenior Lecturer at Department of Ship Power Plants and Systems of the Danube Institute of the National University "Odesa Maritime Academy".At this Institute he had received M.Tech degree in2013. Presently pursuing his $\mathrm{PhD}$ andhis research interests includedredging on rivers and lakes, technical systems for underwater soil mechanical destruction, technical systems on vessels for multiphase flows 0000-0002-3979-4923. E-mail: E-1mail: 